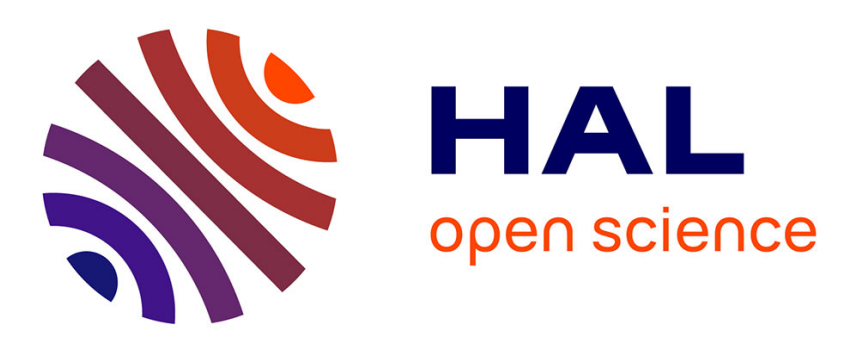

\title{
Power loss models for the portable phone "Pointel" in a typical indoor environment
}

Gheorghe Zaharia, Ghaïs El Zein, Jacques Citerne

\section{To cite this version:}

Gheorghe Zaharia, Ghaïs El Zein, Jacques Citerne. Power loss models for the portable phone "Pointel" in a typical indoor environment. IEEE-VTC International Conference, Stockholm, 1994, Jun 1994, Stockholm, Sweden. pp.892-895, 10.1109/VETEC.1994.345219 . hal-00875642

\section{HAL Id: hal-00875642 https://hal.science/hal-00875642}

Submitted on 4 Nov 2013

HAL is a multi-disciplinary open access archive for the deposit and dissemination of scientific research documents, whether they are published or not. The documents may come from teaching and research institutions in France or abroad, or from public or private research centers.
L'archive ouverte pluridisciplinaire HAL, est destinée au dépôt et à la diffusion de documents scientifiques de niveau recherche, publiés ou non, émanant des établissements d'enseignement et de recherche français ou étrangers, des laboratoires publics ou privés. 


\title{
Power loss models for the portable phone "Pointel" in a typical indoor environment
}

\author{
Gh. Zaharia, G. El Zein and J. Citerne \\ Laboratoire Composants \& Systèmes pour Télecommunications \\ URA CNRS 834, INSA, 35043 Rennes Cédex, FRANCE
}

\begin{abstract}
Using a simplitied and improved measurement system operating in the frequency domain, a typical obstructed line-of-sight (OLOS) indoor environment is fnvestigated. From the measured data, three large-scale models for the power-distance relatfonship are dlscussed. In order to obtain a comparison between these models and to select the most accurate model, two criteria are proposed: the correlathon coefticient and the Euclidean distance between the mensured and the estimated power loss values. These two criteria indicate the same hierarchy for the considered models.
\end{abstract}

\section{INTRODUCTION}

The use of the portable phones or the wireless local area networks within buildings requites a study of the indoor radio propagation. The main objective of the indoor radio wave propagation measurements is to determine the radio coverage and the data rate limitations in various buildings. The radio coverage is related to the power-distance relationship in the area, while the data rate is limited by the frequency selective fading multipath characteristics of the channel [1].

The measurements described in this paper were performed for the portable phone Pointel, developed by SAT-Paris. This system operates in the $864-868 \mathrm{MHz}$ frequency band and has 40 adjacent channels, each one with $100 \mathrm{KH}_{2}$ bandwidth. The aim of these measurements is to delermine the radio coverage in some typical indoor environments. In a previous paper [2], three indoor environments with both line-of-sight (LOS) and obstruction of the direct path were analysed. In this paper, a new OLOS environment is considered. From the measured data, three large-scale models for the powerdistance relationship are presented and compared.

\section{DESCRIPTION OF THE MEASUREMENTS}

The measurement system is built up around an HP $8753 \mathrm{C}$ network analyzer which generates a swept frequency signal from $864 \mathrm{MHz}$ to $868 \mathrm{MHz}$ in 801 equally spaced sceps and analysis the received signal. The output of the network analyzer (fig. 1 ) is connected to the transtritting (Tx) anterna with $3.5 \mathrm{dBi}$ gain through a $50 \mathrm{~m}$ coaxial cable with $8 \mathrm{~dB}$ attenuation. The calibration is petformed at the output of this cable. The power of the signal transmitted by the first port of the HP $85046 \mathrm{~A}$ $S$-parameter test set is $+20 \mathrm{dBm}$. Due to the attentation of the $50 \mathrm{~m}$ coaxial cable contnected between the transmitting antenoa and the port $l$, the actual transmitted power is +12 $\mathrm{dBm}$. The signal from the fixed receiving antenna is returned through a $4.5 \mathrm{~m}$ coaxial cabje to the network analyzer in order to determine the $S_{21}$ parameter. For the power loss measurements, for each location of the $\mathrm{Tx}$ antenna, the magnitude of $S_{21}$ must be recorded. The measured data are read by the computer Tektronix 4041 via the IEEE-488 interface bus and stored on the hard disk (TEK 4041 Disk Drive Unit) for further analysis.

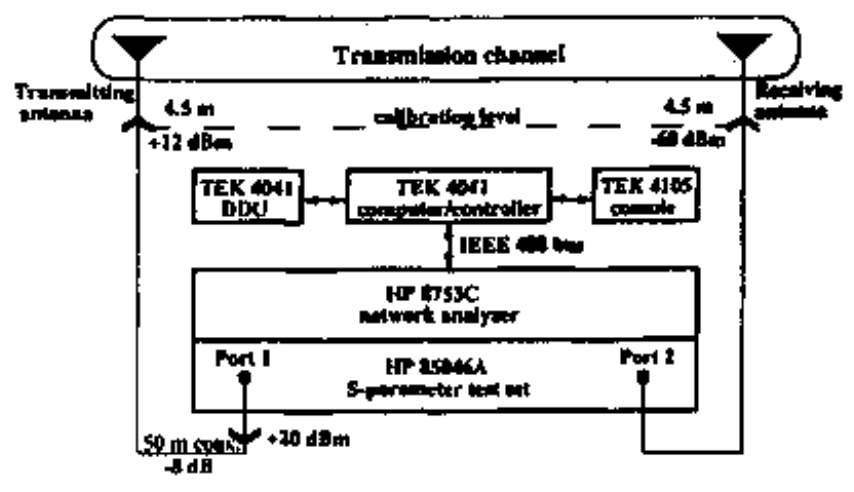

Fig. I, Measurgment system

In order to obtain sufficient data in a reasonable time, the acquisition program presents some important features [3]. The data transfer is realised in the fastest fomat of the nelwork analyzer: the internal binary format. This solution reduces the transfer time at $0.39 \mathrm{~s}$ (for 801 values). The data is received in a string variable and recorded with a low-level statement. Therefore, the recording time is reduced at $1.67 \mathrm{~s}$ for one curve (801 points).

Unfortunately, the computer can not use the data recorded in this format. Therefore, after the end of the 
measurement campaign, in the laboratory (practically, during the night), the data must be returned to the network analyzer and transformed in the ASCII format. A new transfer to the computer permits to create ASCII files in a separate zone of the hard disk. The main advantage of this strategy is the important reduction of the total tire required for a measurement during the measurement campaign.

Another feature of the acquisition program is the utilisation of the learn string to read and store the state of the network analyzer. The learn string includes all front parel settings. Before the measurement campaign, it can be read by the computer from the network analyzer via the [EEE-488 interface and recorded in a file. At the beginning of the measurements, the leam string is read from this file and putted back into the network anajyzer via the IEEE488 interface.

The time required for the set-up of this measurement system can be further reduced by reading the calibration data. This operation can be performed only once, in the laboratory. At the beginning of a measurement campaign, after the instrument state, the program can also testore the calibration, so a slow operation can be avoided.

A final feature is the utilisation of this program as a part of the special program AUTOLD of the Tektronix 4041. This program is automaticatly loaded and run. Thus, the task of the operator is much simplified.

Fig. 2 presents the indoot environment chosen for these measurements, located in the first floor of the principal building of INSA (National Institute of Applied Sciences). The $\mathrm{Rx}$ antenna was placed at one extremity of the first room and the $T x$ antenna was moved at several locations on a straight line, in four successive rooms. For each room, 50 locations for the $\mathrm{Tx}$ antenna were chosen on a logarithmic scale. Both antennas are $\lambda / 4$ units which exhibit an omniditectional radiation pattern in the horizontal plane and approximately figure-eight shaped beam in the vertical plane. They were placed at the same height $\mathrm{H}$, therefore the influence of the radiation pattern on the received power was eliminated for the direct path. For the antennas height, two values were considered: $\mathrm{H}=1.5 \mathrm{~m}$ and $H=1.9 \mathrm{~m}$. During the measurements, both antennas were kept fixed.

Concerning the time invariance of the channel, the measurements were performed during the week-end, in order to avoid the effects of the presence of people. The surrounding environment was kept stationary by preventing movements during the measurements.

\section{DATA ANALYSIS}

\section{Global analysis}

For power loss measurements, for each frequency $t_{j}$ ( $1 \leq \mathrm{j} \leq \mathrm{m}$ ) chosen in the considered frequency band and for each position of the $T x$ antenna, placed at a distance $d ;$ ( $1 \leq \mathrm{i} \leq \mathrm{n}$ ) from the $\mathrm{Rx}$ antenna, a value pij for the power loss is obtained. For each distance $d_{i}$, the m power loss values $P_{i j}$ can be averaged. Consequently, an average power loss $\bar{P}\left(d_{j}\right)$ is obtained. As usual $[1,2,4]$, assuming that, for a given distance $d$ between antennas, the average power loss can be expressed as:

$$
\vec{P}(d)=A d^{\alpha}
$$

when the logarithm of (1) is taken, the following linear relationship results:

$$
\bar{P}(d B)=A(d B)+\alpha\left[10 \log _{1} \alpha(d)\right]
$$

Using a linear fegression analysis [5] between the average power loss and the distance, the parameters $A$ and $\alpha$ can be computed. Due to the calibration, the attenuation of the coaxial cable was eliminated, so A obtained above represents a realistic value.

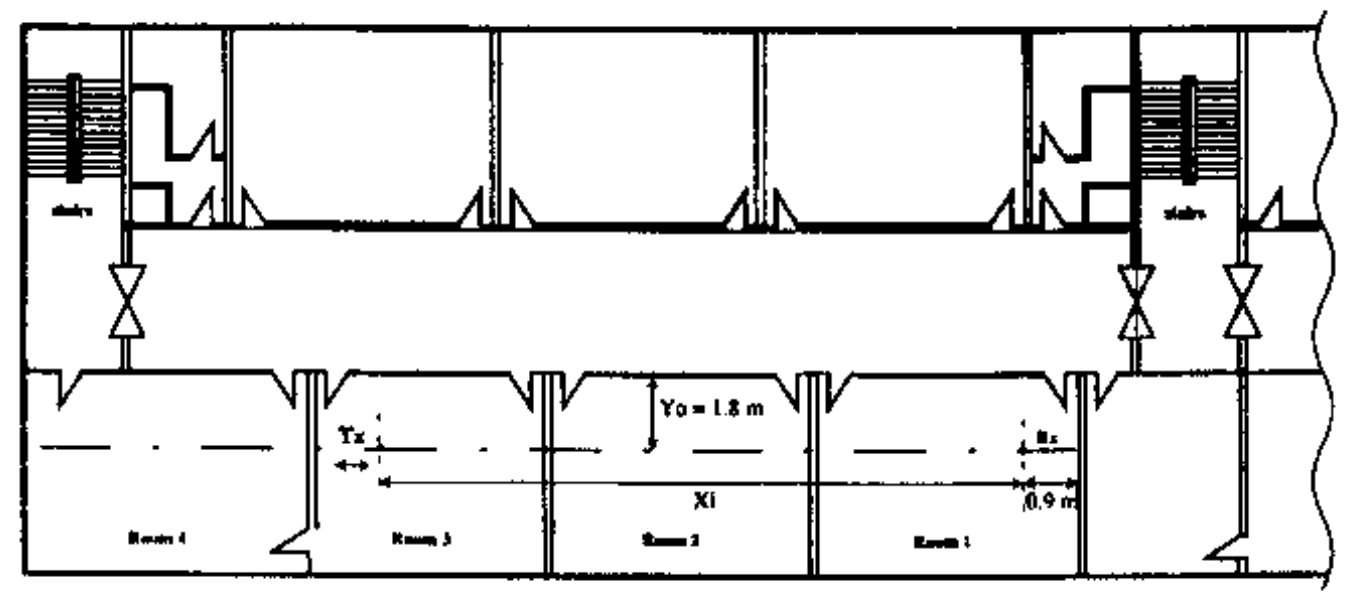

Fig. 2. Indoor envifonment considered in the building of INSA 
For $H=1.5 \mathrm{~m}$, the linear regression analysis gives $\alpha=2.564$ and $A=35.64 \mathrm{~dB}$. The standard deviation of the average power loss from the regression estimates is ems $=5.577 \mathrm{~dB}$. The correlation coefficient $r=0.89$ indicates that increasing power loss is highly correlated with increasing distance. Similar results are obtained for $\mathrm{H}=1.9 \mathrm{~m}$.

\section{Analysis for each room with an unique exponent}

This analysis takes into account the attenuations $P_{A B}$. $P_{B C}$ and $P_{C D}$ introduced by the walts which separate the four rooms. As in [6], if we consider an unique exponent $\alpha$ for each room, due to these attenuations, the power loss can be modelled as:

$$
\begin{array}{ll}
\bar{P}(d)=A+\alpha\left[10 \log _{10}(d)\right], & \text { for Room } 1 \\
\bar{P}(d)=B+\alpha\left[10 \log _{10}(d)\right], & \text { for Room } 2 \\
\bar{P}(d)=C+\alpha\left[\operatorname{lolog}_{10}(d)\right], & \text { for Room } 3 \\
\bar{P}(d)=D+\alpha\left[\operatorname{lolog}_{10}(d)\right], & \text { for Room } 4
\end{array}
$$

The above relations allows us to accept different attenuations for the separating walls:

$$
\begin{aligned}
& P_{A B}=B-A \\
& P_{B C}=C-B \\
& P_{C D}=D-C
\end{aligned}
$$

Therefore this model is more general and describes better the power-distance relationship. If:

$$
\mathbf{B}-\mathbf{A}=\mathbf{C}-\mathbf{B}=\mathbf{D}-\mathbf{C}
$$

one can obtain the model described in [6].

For the same height $H=1.5 \mathrm{~m}$, the obtained results are given in fig. 3. The vertical dotted lines represent the walls. This figure shows a scatter plot of the power loss versus distance on a log scale and the MMSE lines fitted to the data.

This new power loss model indicates smaller values for $\alpha$ ( 1.55 for $H=1.5 \mathrm{~m}$ and 1.77 for $H=1.9 \mathrm{~m}$ ), while the global model gives more important values (2.56 for $\mathrm{H}=1.5$ $\mathrm{m}$ and 2.45 for $\mathrm{H=1.9} \mathrm{m}$ ), due to the walls attenuations. It is interesting to note that similar smajler values for $\alpha$ (about 1.55) were obtained on the corridor, at the same floor of the environment considered in fig. 2 [2]. For the corridor, for all measurements, the line-of-sight (LOS) was essured.

The results obtained with this model suggest that the propagation conditions for this OLOS indoor environment resemble those of the corridor (LOS environment). The difference consists in the presence of the separating walls which behave as attenuators. Using the results given in fig. 3 and the relations $(7)-(9)$ it is possible to estimate their attenuations: $P_{A B}=4.57 \mathrm{~dB}, P_{B C}=6.25 \mathrm{~dB}$ and $P_{C D}=$ I. $13 \mathrm{~dB}$. The first values reflect a real situation: the second wall has practically the same thickness as the first one bitt on each side it has a blackboard with a metallic support, while the first dividing wall has only one blackboard (with one metallic support). Therefore, $\mathrm{PBC}_{\mathrm{BC}}>\mathrm{P}_{\mathrm{AB}}$.

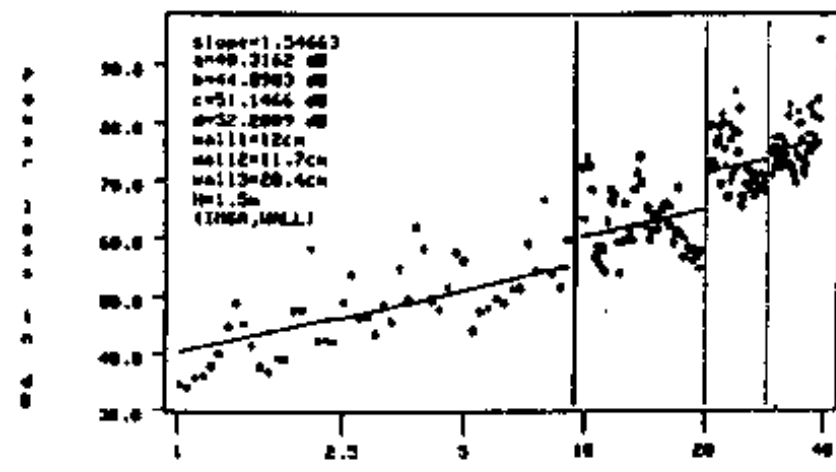

momet minde

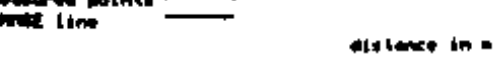

Fig. 3. Power loss versus distance on a log scale (unique exponent)

One can also note that the thickness of the third dividing wall is about the double of the thickness of the first dividing wall. Each one has an identical blackboard with an identical metallic support. Therefore, it is natural to expect $\mathrm{PCD}_{\mathrm{CD}}>\mathrm{PBC}_{\mathrm{BC}}$. However, the value obtained from measurement is smaller than $\mathbf{P}_{\mathrm{BC}}$. This can be determined by the important distance between the $\mathrm{Rx}$ antenna and the third dividing wall.

The obtained value for PCD suggests to repeat the measurements with the $R x$ antenna placed in the third room, next to the second dividing wall and $\mathrm{Tx}$ antenna moved at severat locations on a straight line, in the third and the fourth room (so a similar scenario used for $P_{A B}$ ). In order to obtain a better estimation for $\mathrm{P}_{\mathrm{BC}}$, the same scenario can also be used for the second wall. Using the new values for $P_{B C}$ and $P_{C D}$ it is possible to repeat the analysis with an unique exponent in order to obtain a more accurate model.

In fig. 3 one can also note the important variation of the power loss with the distance. In the corridor, these variations are less important. This suggests the presence of the steady-stead waves, due to multiple reflections on the djviding walls.

\section{Analysis for each room}

In this case. the regression analysis is performed independently for the data obtained in each room. This 
time we drop the idea of an unique exponent. The analysis gives a value for $A_{k}$ and $\alpha_{k}$ for each foom $k$ :

$$
\ddot{P}(d)=A_{k}+\alpha_{k}[\mid O \log 1(d)], \quad \text { for } \operatorname{Room} k, \quad k=\overline{1,4}
$$

The obtained results are given in Table 1. For the first room, the restilts are quite well. Due to the steady-stead waves, the root mean square error (ems) is quite important, while the comelation coefficient $r$ is quite small, while the global analysis gives a about 0.9 . For both heights, the slope $\alpha$ is about 2 , so the propagation conditions resemble those associated with free-space.

\section{TABLE I}

RESULTS OF THE ANALYSIS FOR EACH ROOM

\begin{tabular}{|c|c|c|c|c|c|c|c|c|}
\hline \multirow{2}{*}{ Putan. } & \multicolumn{2}{|c|}{ Room I } & \multicolumn{2}{|c|}{ Room 2} & \multicolumn{2}{|c|}{ Room 3} & \multicolumn{2}{|c|}{ Room 4} \\
\hline & $H=1.9$ & $H=1.9 \mathrm{~m}$ & $H=1.5 \mathrm{~m}$ & $\mid \neq=1.9 \mathrm{~m}$ & $14=1.9 \mathrm{~m}$ & $H=1.9 \mathrm{n}$ & $\mathrm{t}=1.5 \mathrm{~m}$ & $\mathrm{H}=1.9 \mathrm{~m}$ \\
\hline & 2.016 & & -2.06 & 0,363 & -5.56 & -0.54 & 4.759 & 4.062 \\
\hline$A(d B)$ & .07 & 39.11 & 6.14 & 59.58 & 149.35 & 90.22 & 9.25 & 12.05 \\
\hline$I$ & 0.746 & 0.749 & -0.34 & 0072 & $-0.49 \mathrm{~d}$ & -0.053 & 0.395 & 0.337 \\
\hline $\mathrm{ms}(\mathrm{dB})$ & 5.078 & 4.804 & 4. 989 & 4.488 & 4.064 & 4,239 & 4.081 & 4.194 \\
\hline
\end{tabular}

For the other roorns, the correlation is week. For example, for the second room, the correlation and the slope are negative. Due to the important attenuation of the metallic support of the blackboard, the received signal after the first wall is quite weak. This attenuation is less important with increasing distance, so in the middle of the room the power loss is less important. This can explain the negative value of the slope and the correlation coefficient.

\section{COMPARISON BETWEEN THE MODELS}

In the previous section, from the measured power loss

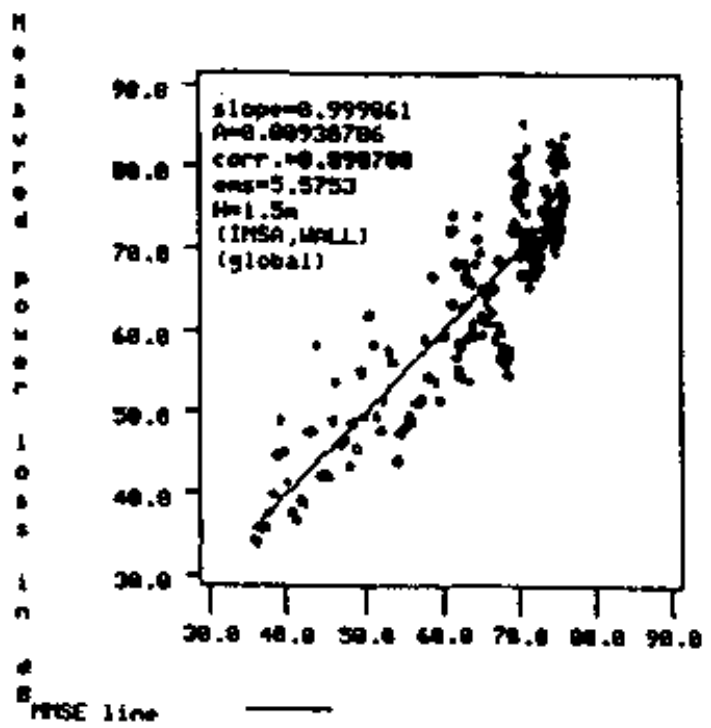

$$
\text { Etimated poner lost in } a
$$

Fig-4. Comelotion belween the neasured and estimated powtr loss values (H+1.5 m) values, three large-scale models for the power lossdistance relationship were described, In this section, two different criteria are proposed: the cortelation coefficient between the measured and estimated power loss values and the Euclidean distance between these two parameters, thought as two vectors.

For the first model and for $\mathrm{H}=1.5 \mathrm{~m}$, the results of the regression analysis are shown in fig. 4 . Similar results were obtained for the other models. All the results are given in Table 2.

TABLE 2

\begin{tabular}{|c|c|c|c|c|c|c|}
\hline \multirow{2}{*}{ Pariam. } & \multicolumn{2}{|c|}{ Model 1} & \multicolumn{2}{|c|}{ Model 2} & \multicolumn{2}{|c|}{ Model 3} \\
\hline & Het.s.s & $\mathrm{H}=1.9 \mathrm{~m}$ & $\mathrm{H}=15 \mathrm{n}$ & $\mathrm{Hm} 1.9 \mathrm{~mm}$ & Hat.5n & $H=4.9 \mathrm{O}$ \\
\hline I & 0.891 & 0,909 & 0,908 & 0.919 & 0,928 & 0.923 \\
\hline $\operatorname{tns}(d B)$ & 5.575 & 4,794 & 5.147 & 4.527 & 4.569 & 4,431 \\
\hline
\end{tabular}

COMPARISON BETWEEN THE MODELS

The two criteria indicate the same hierarchy for the proposed models: 1-2-3 (the third model is the best). This is a normal result, because the third model uses 8 independent parameters $(A, B, C, D$ and one exponent for each room).

\section{CONCLUSION}

Using an improved measurement system, a typical indoor environment has been chosen for experimental investigation. Three large-scale models for the powerdistance relationship were considered. The comparison between these models indjcates that the thind model gives the best cotrelation and the smallest Euclidean distance between the measured and estimated power loss values. Using these results, the radio coverage in different buildings can be obtained with an enough accuracy.

\section{REFERENCES}

[I] S.J. Howard and K. Pablaru, Measurement and enalysis of tho

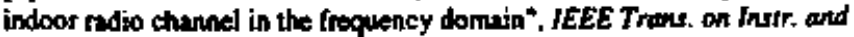
Heas. Vol. IM-39, 1990, pp.75l-75s

[2] Gh. Zhharia, G. EJ Zein and J. Cireme, Aadycis of the indace propagation loseses for the porthle pbone Pointel" in IEEE AP-S Int. Symp. Dig., Amn Abor MI, 1993, pp. I064-1072

[3] Gh. Ztheria, G. El Zein thd J. Cileme, "An improved froduency domin mentwement ortem for the indoos rodio chunde, is Proc of the SCS 93 inl. Symp. lai, Rommit, now. 1993

[4] P.F.M. Smulders, A.G. Wagemans, wideband indoor radio propegation meaturements it 58 GHz" Electron.Letl., Vol.28, No.13, 1992. pp. 1270-1272

[5] Ustowitz, H.: Signal theory and random procestes, Artech House, Washington, 1983, Ch.7

[6] I.F. Lafortune and M. Lecours, "Messurement and modeling of propaction losses in a building at $900 \mathrm{MHz}$, JEEE Trater, an Veh. Techuol Vol. VT-39. 1990, pp. I0J-tas 